\title{
Politicians, Governed vs. non-Governed Interest Groups and Rent
}

\section{Dissipation $^{1}$}

\author{
by \\ Gil S. Epstein \\ Bar-Ilan University, Israel and CReAM, London, IZA, Bonn \\ and \\ Yosef Mealem \\ Netanya Academic College, Netanya, Israel
}

\begin{abstract}
Government intervention often gives rise to contests and the government can influence their outcome by choosing their type. We consider a contest with two interest groups: one that is governed by a central planner and one that is not. Rent dissipation is compared under two well-known contest success functions: the generalized logit and the all-pay auction. We also consider the case in which the government can limit the size of the non-governed interest group in order to determine the scope of rent dissipation, with the goal of either increasing the rent obtained by the government or reducing the wasted resources invested in the contest.
\end{abstract}

Keywords: Rent dissipation, central planner, contest, all-pay auction, generalized logit contest success function.

JEL classifications: D70, D71,D72

\footnotetext{
${ }^{1}$ Financial support from the Adar Foundation of the Department of Economics of Bar-Ilan University is gratefully acknowledged.

* Corresponding author: Tel: 972-52-8550-407, E-mail: gil.epstein@biu.ac.il
} 


\section{Introduction}

When the government proposes a new policy or project, it may have differential effects on various groups in society. This can give rise to contests between interest groups and as a result the government is often a leading player in such contests. Knowing this, the government can play the role of contest designer by determining the number of players in a contest, the type of contest to be played and the stakes of the contest. ${ }^{2}$

One of the main concerns of the contest designer is to choose the optimal type of contest. Two main types of contests, as represented by their contest success functions (CSF), are considered in the literature: the lottery proposed by Tullock (1980) and the all-pay auction contest (hereafter: APA) which is a special case of the Tullock CSF (see Konrad ,2009, and references within). One reason for the popularity of these CSF functions is their appealing axiomatization, as discussed in Skaperdas (1996), Clark and Riis (1998), Blavatskyy (2010), Corchon and Dahm (2010) and Jia $(2008,2010){ }^{3}$ For a discussion of the simple lottery, see Hirshleifer and Riley (1992), Fullerton and McAfee (1999), Baye and Hoppe (2003) and Franke et al. (2011).

Most of the literature on optimal contest design has focused on the choice of the contest prize (Glazer and Hassin, 1988; Runkel, 2006; Singh and Wittman, 1998; Epstein and Nitzan, 2002, 2006a, 2006b, 2007); the set of contestants (Baye et al., 1993; Amegashie, 2000; Moldovanu and Sela, 2006; Taylor, 1995); the set of contestants and the prize system (Che and Gale ,2003); the structure of multi-stage contests (Gradstein ,1998; Gradstein and Konrad ,1999; Amegashie ,2000); caps on political lobbying (Che and Gale ,1998); and the CSF, which relates the contestants' efforts to their probabilities of winning (Che and Gale ,1997; Nti ,1997, 2004).

In this paper, we consider two interest groups: one that is governed by a central planner and one that is not. For example, consider the case of a firm (a governed interest group) that is defending its market power over consumers (a nongoverned interest group) who are challenging that power (see, for example, Baik,

\footnotetext{
${ }^{2}$ A major focus of the contest literature has been the issue of how changing the parameters of the contest (number of the players, valuations and abilities of the contestants and the nature of the information they possess) will alter the equilibrium efforts and the extent of relative prize dissipation (Hillman and Riley ,1989; Hurley and Shogren ,1998; Konrad ,2002; Nitzan ,1994; Nti ,1997). In addition, attention is paid to the effect of the changes made in these parameters on the contestants' expected payoffs (Gradstein ,1995; Nti ,1997). Moreover, a major effort has been made to clarify the different levels of rent under-dissipation in contests (Gradstein and Konrad ,1999; Kahana and Nitzan ,1999; Konrad ,2004; Konrad and Schlesinger ,1997; Nitzan ,1994; Nti ,1997).

${ }^{3}$ See Munster (2009) for a generalization of the axiomatic approach to group CSFs.
} 
1999; Ellingsen, 1991; Epstein and Nitzan, 2003, 2007 and Schmidt, 1992). The firm is a single entity, while the consumers are a diffuse group. In another example (see Epstein and Nitzan, 2006a, 2006b, 2007), employers are defending the minimum wage level against a union that is seeking to increase it.

Riaz, Shogren and Johnson (1995) present a general model of rent-seeking for a public good by expanding the rent seeker's consumption bundle to include preferences over a public good and a private good. Their results suggest that collective rent-seeking is positively related to group size. Although free riding exists within a group, the tradeoff is not one-for-one. Furthermore, rent seeking is found to increase with wealth.

In determining the type of contest, the contest designer (a politician, legislator, regulator, etc.) influences the scope of rent dissipation. Rent dissipation can be viewed as a benefit to the contest designer, in that he receives the resources invested by the interest groups (see for example, Persson and Tabellini, 2000; Grossman and Helpman, 2001 and Epstein and Nitzan, 2007). Alternatively, rent dissipation is often perceived as involving the wastage of resources invested in winning the contest. Reducing the amount of wasted resources, i.e. rent dissipation, is thus welfare enhancing. ${ }^{4}$

A great deal of effort has been made in the literature to determine maximal rent dissipation using various types of discrimination between the contestants. Discrimination can be multiplicative, as in Epstein et al. (2011, 2012), Franke (2012), Franke et al. (2011), Konrad (2002) and Lien (1990), additive, as in Li and Yu (2012), or direct via differential taxation of the contested prize, which affects the contestants' actual prize valuations, as in Mealem and Nitzan (2012a, 2012b).

As mentioned, in this paper we consider two interest groups: one that is governed by a central planner and one that is not. While the objective of the contest designer is similar to that in Franke et al. $(2011,2012)$ and others, in that it attempts to achieve maximal rent dissipation, our approach differs from the literature in two aspects: First, Franke et al. (2011) determines the optimal level of discrimination in the contest such that it maximizes rent dissipation and as a result the planner ends up encouraging the weaker player. Second, Franke et al. (2012) also showed that rent dissipation under APA is higher than under the simple lottery. In contrast to these

\footnotetext{
${ }^{4}$ Note that Hurley (1998) mentions that rent dissipation can be a misleading measure of the welfare implications of a contest when players have asymmetric valuations.
} 
models and others that achieve maximal rent dissipation through the types of discrimination mentioned above, we emphasize a different type of discrimination, in which the contest designer limits the size of the non-governed interest group and thus determines the level of rent dissipation.

The first question we wish to answer is how the size of the non-governed interest group affects the rent dissipation that will be obtained by the contest designer in the two types of contest: APA versus logit. In addition, the contest designer can also limit the size of the non-governed interest group in order to maximize the resources invested in the contest (for the benefit of the contest designer) or to minimize the wasted resources invested in the contest. Therefore, the second question to be answered is what is the optimal group size $\mathrm{e}^{5}$ from the point of view of the contest designer. The following examples will help to demonstrate the relevance of the model:

1. The government, via a central land planning authority (the central planner), holds an auction of land on which a new neighborhood is to be built. The future neighborhood is located next to a nature reserve and therefore there is opposition from a green group that wishes to keep the area natural. The contest then is between the green group and the winners of the land auction. In this case, the land planning authority, as the central planner, has the power to determine the number of those who will receive land in the auction.

2. The Ministry of Communication decides to issue a tender in order to choose a number of new providers of cellular phone service. In order to provide this service, a cellular provider will have to place antennas in a location that belongs to a private non-profit organization (or a private individual). The contest is then between the non-profit organization and the cellular providers who win the tender. In this case, the Ministry of Communication, as the

\footnotetext{
${ }^{5}$ Esteban and Ray (2001) and Baik (2007) study contests with group-specific public goods prizes. Esteban and Ray (2001) consider a collective action with three features: it is undertaken in order to counter similar action by competing groups, marginal individual efforts are increasingly costly and collective prizes are seen to have mixed public-private characteristics. All individuals in a group are assumed to have the same benefit from the public good, while private goods benefit the group as a whole. Thus, increasing the size of the group decreases the benefit to each of its members. Esteban and Ray (2001) show that there exist conditions under which increasing the size of the group will increase the probability of winning, even though the benefit per member has decreased. Baik (2007), on the other hand, presents a model in which $n$ groups compete to win a group-specific public goods prize, the individual players choose their effort levels simultaneously and independently and the probability of winning depends on the level of the groups' efforts.
} 
central planner, can determine the number of cellular providers that can compete in the tender. ${ }^{6}$

Understanding how a change in the contest success function will affect the rent dissipation of the contest may help to understand why in some contests the contest designer will choose APA and in others a logit-type contest.

With regard to the type of lottery preferred by the planner, given the size of the group, we provide conditions under which the APA contest success function can create higher or lower rent dissipation than the generalized logit contest success function. Our results shed light on the objectives of the contest designer via the choice of the contest success function and the size of the non-governed interest group. Our results depend, to some extent, on the size of the non-governed interest group. However, if the stakes are similar in size for both groups, then rent dissipation under the APA will be greater regardless of the size of the non-governed interest group.

With regard to the optimal size of the group from the perspective of the contest designer, it is shown that in the generalized logit contest, if the contest designer wishes to maximize rent dissipation, then he will limit the size of the nongoverned interest group. If, on the other hand, he wishes to reduce the amount of resources wasted in the contest, it may be optimal (especially in large societies) not to limit the size of the non-governed interest group. These results may indicate the extent to which a contest designer perceives rent dissipation in a positive light, i.e. the weight he assigns to rent dissipation in his objective function. A society that limits the size of the non-governed interest group is governed by a contest designer who wishes to maximize rent dissipation and is concerned less with social welfare.

The remainder of the paper is organized as follows: Section 2 presents the model. Section 2.1 describes equilibrium and rent dissipation for the generalized logit contest success function and for APA and at the end of the section we compare the rent dissipation in the two situations (Proposition 1). Section 2.2 presents the optimal group size that either maximizes or minimizes the rent dissipation of the contest (Proposition 2). Concluding remarks are presented in Section 3. The proofs of the two propositions are presented in the appendix.

\section{The Model}

\footnotetext{
${ }^{6}$ In footnote 7, we present additional examples that demonstrate the relevance of the model.
} 
Consider a contest in which two groups compete for a prize. As in Epstein and Nitzan (2007), suppose that a status quo policy is challenged by one of the interest groups and defended by the other.

The defending group consists of one player and therefore in what follows it is called the governed interest group while the challenging group consists of $N$ players and therefore it is called the non-governed interest group. ${ }^{7}$ In the two examples presented in the Introduction and the two examples presented in footnote 7 , the governed interest groups are the greens, the private non-profit organization, the provider of school supplies and the supermarket chain while the non-governed interest groups are the landowners, the cellular providers, the employees of the office supplies provider and the consumers, respectively.

Each player in the non-governed interest group receives a benefit of $n$ if he wins the contest while the player in the governed interest group (the monopoly) receives a benefit of $m$. Each player $i(i=1, \ldots, N)$ in the non-governed interest group invests $x_{i}$ resources in the effort to change the status quo and the player in the governed interest group invests $y$ units to defend it.

In order to calculate the rent dissipation of the contest, we consider two types of contest success functions: the generalized logit function and the APA. We consider each in succession.

\subsection{Equilibrium Rent Dissipation}

Rent dissipation can, on the one hand, be viewed as a benefit to the contest designer, in the case that the resources invested by the groups accrue to him. On the other hand, rent dissipation is often perceived as a waste of the resources invested by the interest

\footnotetext{
${ }^{7}$ Two additional examples that demonstrate the relevance of the model are related to the minimum wage and monopoly: 1 . The government outsources the provision of office supplies to the schools to a single supplier. The government is indirectly responsible for the supplier's workers, in that it wishes to determine a minimum wage for them. The contest is between the management of the company and its workers who receive the minimum wage. In this case, the government's determination of the minimum wage to be discussed by the two sides indirectly influences the number of workers who will receive it and therefore the number of "contestants" among the workers. 2. The local government can determine the location of a new supermarket which will operate as a monopoly in the area. The contest is between the supermarket chain, which would like to charge high prices, and consumers, who would like to see lower prices. The farther (closer) is the supermarket from the residential area, the lower (higher) the number of consumers that will shop there. In determining the location of the supermarket, the local government has an indirect influence on the number of consumers and therefore on the number of "contestants" among them.
} 
groups in the contest. Therefore, reducing rent dissipation will often lead to welfare enhancement. We therefore wish to examine rent dissipation in each type of contest.

\subsubsection{The Generalized Logit Contest Success Function}

The probability that the new policy will be accepted and the status quo changed is denoted by $\operatorname{Pr}_{N}$ and calculated from the generalized logit contest success function (Tullock, 1980):

$$
\operatorname{Pr}_{N}=\frac{\sum_{1}^{N} x_{i}^{\alpha}}{\sum_{1}^{N} x_{i}^{\alpha}+y^{\alpha}} \text { with } 0<\alpha<1 \text {. }
$$

If neither group invests in the contest $\left(x_{i}=y=0\right)$, then each has an equal probability of winning $\left(\operatorname{Pr}_{N}=0.5\right)$. We restrict our analysis to the case where $0<\alpha<1^{8}$ (see Epstein and Mealem ,2009, 2011). The expected payoff of each of the players in the non-governed interest group equals:

$$
E\left(U_{i}\right)=\frac{\sum_{1}^{N} x_{i}^{\alpha}}{\sum_{1}^{N} x_{i}^{\alpha}+y^{\alpha}} n-x_{i} \quad i=1, \ldots, N
$$

and the expected payoff of the governed interest group equals:

$$
E\left(U_{d}\right)=\frac{y^{\alpha}}{\sum_{1}^{N} x_{i}{ }^{\alpha}+y^{\alpha}} m-y .
$$

Define $k$ as the ratio of the stake of each player in the non-governed interest group to that of the governed interest group: $k=\frac{n}{m}$. Solving the first-order conditions

\footnotetext{
${ }^{8}$ For $\alpha=1$, Baik (2007) applies.
} 
for each of the players in the two groups (it can be verified that the second-order conditions hold), we obtain that the resources invested in equilibrium are as follows:

$$
x_{i}^{*}=\frac{\alpha n k^{\alpha}}{N^{\alpha}\left(N^{1-\alpha} k^{\alpha}+1\right)^{2}}, y^{*}=\frac{\alpha N^{1-\alpha} m k^{\alpha}}{\left(N^{1-\alpha} k^{\alpha}+1\right)^{2}}
$$

Using (4), we can calculate rent dissipation $(R D)$ under the generalized logit CSF:

$$
R D_{L}^{*}=N x_{i}^{*}+y^{*}=\frac{\alpha N^{1-\alpha} k^{\alpha}(n+m)}{\left(N^{1-\alpha} k^{\alpha}+1\right)^{2}}
$$

\subsubsection{The All-Pay Auction Contest Success Function}

The APA contest success function is given by:

$$
\operatorname{Pr}_{N}\left(\sum_{1}^{N} x_{i}, y\right)=\left\{\begin{array}{llll}
1 & \text { if } & \sum_{1}^{N} x_{i}>y \\
0.5 & \text { if } & \sum_{1}^{N} x_{i}=y \\
& \text { if } & \sum_{1}^{N} x_{i}<y
\end{array}\right.
$$

In equilibrium, the only active player in the non-governed interest group is the one with the highest valuation of the prize and all the other players expend zero effort (see Baik, Kim, and $\mathrm{Na}$,2001). Since all the players in the non-governed interest group have the same valuation, in equilibrium only one of the players in the group is active. It is well known (Baye, Kovenock, and de Vries ,1993) that rent dissipation in this case equals:

$$
\text { For } k \geq 1 R D_{A}^{*}=E\left(\sum_{1}^{N} x_{i}^{*}+y^{*}\right)=\frac{n+m}{2 k}
$$

and

$$
\text { For } k<1 R D_{A}^{*}=E\left(\sum_{1}^{N} x_{i}^{*}+y^{*}\right)=\frac{k(n+m)}{2}
$$




\subsubsection{Comparing the two situations}

We now wish to compare rent dissipation under the two contest success functions: the generalized logit function and the APA.

\section{Proposition 1}

1. $R D_{A}^{*}>R D_{L}^{*}$ if and only if:

a. $\frac{\alpha}{2}<k \leq \frac{2}{\alpha}$
or
b. $k>\frac{2}{\alpha}$ and $N>\left[\frac{\alpha k-1+\sqrt{\alpha k(\alpha k-2)}}{k^{\alpha}}\right]^{\frac{1}{1-\alpha}}$

or

c. $k \leq \frac{\alpha}{2}$ and $\left(N>\left[\frac{\alpha-k+\sqrt{\alpha(\alpha-2 k)}}{k^{1+\alpha}}\right]^{\frac{1}{1-\alpha}}\right.$ or $\left.N<\left[\frac{\alpha-k-\sqrt{\alpha(\alpha-2 k)}}{k^{1+\alpha}}\right]^{\frac{1}{1-\alpha}}\right)$

2. $R D_{A}^{*}<R D_{L}^{*}$ if and only if: ${ }^{9}$

a. $\quad k>\frac{2}{\alpha}$ and $N<\left[\frac{\alpha k-1+\sqrt{\alpha k(\alpha k-2)}}{k^{\alpha}}\right]^{\frac{1}{1-\alpha}}$

or

b. $\quad k \leq \frac{\alpha}{2}$ and $\left[\frac{\alpha-k-\sqrt{\alpha(\alpha-2 k)}}{k^{1+\alpha}}\right]^{\frac{1}{1-\alpha}}<N<\left[\frac{\alpha-k+\sqrt{\alpha(\alpha-2 k)}}{k^{1+\alpha}}\right]^{\frac{1}{1-\alpha}}$

For proof, see the appendix.

\footnotetext{
${ }^{9}$ Based on the calculations presented in the appendix and according to Part 2.a in Proposition 1, there may exist combinations of $k$ and $\alpha$ for which the condition $N<\left[\frac{\alpha k-1+\sqrt{\alpha k(\alpha k-2)}}{k^{\alpha}}\right]^{\frac{1}{1-\alpha}}$ does not hold. However, according to Part 2.b in Proposition 1 there exists an interval of values of $N$ that satisfies the condition. In order to prove this, we need to show that the RHS of the inequality in Part 2.b is greater than one. Since $k \leq \frac{\alpha}{2}$, it holds that $\frac{\alpha-k+\sqrt{\alpha(\alpha-2 k)}}{k^{1+\alpha}} \geq \frac{\alpha-0.5 \alpha+\sqrt{\alpha(\alpha-2 k)}}{(0.5 \alpha)^{1+\alpha}} \geq \frac{\alpha-0.5 \alpha}{(0.5 \alpha)^{1+\alpha}}=\left(\frac{2}{\alpha}\right)^{\alpha}>1$.
} 
Proposition 1 implies that if the stakes are similar $\left(\frac{\alpha}{2}<k \leq \frac{2}{\alpha}\right)$, APA will generate higher rent dissipation; if not, then the result depends on the size of the non-governed interest group. The intuition behind this result is related to the optimal size of the nongoverned interest group, which we will return to after developing some additional results (specifically, Proposition 2 in section 2.2).

Since $0<\alpha<1$, the following corollary follows from Part 1.a of Proposition 1:

Corollary: If $0.5 \leq k \leq 2$, then $R D_{A}^{*}>R D_{L}^{*}$ regardless of $N$.

\subsection{Optimal group size}

We now consider the optimal group size that maximizes or minimizes the rent dissipation of the contest. The government can limit the size of the non-governed interest group in the contest, with the purpose of either maximizing the resources invested in the contest (for the benefit of the contest designer) or minimizing the resources wasted in the contest.

As shown above, only in the case of the generalized logit function (as opposed to the APA) is rent dissipation a function of group size (see Equations (5) and (7)). We therefore concentrate on rent dissipation under the generalized logit contest success function: $R D_{L}^{*}=\frac{\alpha N^{1-\alpha} k^{\alpha}(n+m)}{\left(N^{1-\alpha} k^{\alpha}+1\right)^{2}}$.

The size of the non-governed interest group is limited by the size of the population that wishes or is able to be a part of the group. Denote the limit on the size of the non-governed interest group as $N_{P}$ (in the extreme case it may be equal to the size of the population in the economy).

\section{Proposition 2}

Under the generalized logit contest success function:

1. The size of the non-governed interest group that maximizes rent dissipation and the maximum rent dissipation equals: 
a. If $k<1$, then $N^{*}=\operatorname{Min}\left(k^{\frac{\alpha}{\alpha-1}}, N_{P}\right)$. If $N^{*}=k^{\frac{\alpha}{\alpha-1}}$, then $R D_{L}^{*}=0.25 \alpha(n+m)$ and if $N^{*}=N_{P}$, then $R D_{L}^{*}=\frac{\alpha N_{P}^{1-\alpha} k^{\alpha}(n+m)}{\left(N_{P}^{1-\alpha} k^{\alpha}+1\right)^{2}}$.

b. If $k \geq 1$, then $N^{*}=1$ and $R D_{L}^{*}=\frac{\alpha k^{\alpha}(n+m)}{\left(k^{\alpha}+1\right)^{2}}$.

2. The size of the group that minimizes rent dissipation and the minimum rent dissipation equals:

$$
\begin{aligned}
& \text { a. If } \quad\left(k<1 \quad \text { and } \quad N_{P} \geq k^{\frac{2 \alpha}{\alpha-1}}\right) \quad \text { or } \quad k \geq 1, \quad \text { then } \quad N^{*}=N_{P} \quad \text { and } \\
& R D_{L}^{*}=\frac{\alpha N_{P}^{1-\alpha} k^{\alpha}(n+m)}{\left(N_{P}^{1-\alpha} k^{\alpha}+1\right)^{2}}
\end{aligned}
$$

b. If $k<1$ and $N_{P}<k^{\frac{2 \alpha}{\alpha-1}}$, then $N^{*}=1$ and $R D_{L}^{*}=\frac{\alpha k^{\alpha}(n+m)}{\left(k^{\alpha}+1\right)^{2}}$.

For proof, see the appendix.

We can now discuss the intuition behind the results, beginning with the case in which the contest designer wishes to maximize rent dissipation (part 1 of Proposition 2 ). For $k<1$, the maximal rent dissipation under the generalized logit CSF is obtained for $N^{1-\alpha} k^{\alpha}=1$, namely when $n N^{\frac{1-\alpha}{\alpha}}=m$. To understand this result, denote the "power" of the non-governed interest group by $n N^{\frac{1-\alpha}{\alpha}}$ (the stake times the size of the group to the power of $\frac{1-\alpha}{\alpha}$, i.e. the normalized size of the group) and denote the power of the governed interest group by $m$ (the size of its stake). When the groups have the same power, the intensity of the contest (i.e. the effort invested) is maximized. Under the generalized logit CSF, when the groups differ in their power the contest becomes less equal and as a result, less effort is invested in the contest, i.e. rent dissipation decreases. For $k>1$, the power of the non-governed interest group is always greater than that of the governed interest group. This means that a decrease in the size of the non-governed interest group until $N^{*}=1$ reduces the power of the nongoverned interest group relative to that of the governed interest group and thus brings the groups closer together in terms of power. This will increase the intensity of the contest and will lead to greater rent dissipation. 
The intuition in the case that the contest designer is interested in minimizing rent dissipation is as follows (part 2 of Proposition 2). For $k \geq 1$, the contest designer will include as large a population as possible, $N_{P}$, in the non-governed interest group since when $k \geq 1$ the power of the non-governed interest group is always greater than that of the governed interest group. Therefore, an increase in the size of the nongoverned interest group, $N$, will increase its power relative to that of the governed interest group and the groups will become less equal in terms of power. This will decrease the intensity of the contest and thus reduce rent dissipation. For $k<1$, an increase in $N$ from $N=1$ to $N=k^{\frac{\alpha}{\alpha-1}}$ increases the intensity of the contest to the maximum, such that for $N=k^{\frac{\alpha}{\alpha-1}}$ the power of the two groups becomes identical and thus rent dissipation is maximized. Increasing the size of the population beyond $N=k^{\frac{\alpha}{\alpha-1}}$ will increase the power of the non-organized group (i.e. the two groups become less alike) and as a result the intensity of the contest will decrease. Thus, rent dissipation will be minimized at a corner solution: $N=1$ if $N_{P}<k^{\frac{2 \alpha}{\alpha-1}}, N_{P}$ if $N_{P}>k^{\frac{2 \alpha}{\alpha-1}}$ or the planner will be indifferent between them given that $N_{P}=k^{\frac{2 \alpha}{\alpha-1}}$.

On the basis of Proposition 2, we can now explain the results of Proposition 1:

1. From Proposition 2, we conclude that when the stakes are identical, i.e. $k=1$, we obtain that for $N=1$ rent dissipation under the generalized logit CSF is maximized and equals $R D_{L}^{*}=0.25 \alpha(n+m)=0.5 \alpha n$. Under APA, rent dissipation is independent of $N$ and for $k=1$ the maximal value of rent dissipation equals $R D_{A}^{*}=0.5(n+m)=n$. Thus, in the benchmark case of $N=k=1$, we obtain that $R D_{A}^{*}>R D_{L}^{*}$. When we increase $N$, rent dissipation under APA remains unchanged. In contrast, rent dissipation in the generalized logit case decreases since the power of the non-governed interest group increases relative to that of the governed interest group and the groups become less equal in terms of power. This will decrease the intensity of the contest and thus reduce rent dissipation. Thus, if the stakes are equal, we obtain that rent dissipation in the case of APA is greater than in the case of the generalized logit function. Part 1.a of Proposition 1 implies that this result holds for any stake ratio $k$ that is close to one, i.e. $\left(\frac{\alpha}{2}<k \leq \frac{2}{\alpha}\right)$. 
2. We now consider what happens when $k$ is decreased, such that $k \leq \frac{\alpha}{2}$. In the case of APA, the intensity of the contest decreases and thus rent dissipation is reduced. In the case of the generalized logit CSF, the effect of a decrease in $k$ is ambiguous and the outcome depends on the relative power of the contestants. Assume that as a result of a decrease in $k$ the power of the contestants is now equal: $N^{1-\alpha} k^{\alpha}=1$ $\left(n N^{\frac{1-\alpha}{\alpha}}=m\right)$. Thus, the intensity of the contest has increased and as a result rent dissipation under the generalized logit CSF is greater than under APA, i.e. $R D_{A}^{*}<R D_{L}^{*} \cdot{ }^{10}$ In this case, a small change in $N$ (which moves it away from the optimal group size in the interval described in Part 2.b of Proposition 1) will lead to a small decrease in the intensity of the contest under the generalized logit CSF and as a result to a small reduction in rent dissipation. Note that rent dissipation under APA is independent of the size of the non-governed interest group. Since the change in rent dissipation under the generalized logit CSF is small, the result $R D_{A}^{*}<R D_{L}^{*}$ continues to hold. However, under the generalized logit CSF, a large change in $N$ (within the intervals in Part 1.c of Proposition 1), the intensity of the contest will decrease substantially and therefore rent dissipation will be reduced, such that $R D_{A}^{*}>R D_{L}^{*}$.

3. We now consider what happens if $k$ increases such that $k>\frac{2}{\alpha}$. In this case, the value of $R D_{A}^{*}$ relative to $R D_{L}^{*}$ also depends on $N$. Under APA and using the same logic as in 2 above, a sufficient increase in $k$ will substantially reduce the intensity of the contest and thus rent dissipation will decrease. Under the generalized logit $\mathrm{CSF}$, the analysis differs from that presented in 2 above since the power of the non-governed interest group is always greater than that of the governed interest group. Moreover, an increase in $k$ will strengthen the non-governed interest group relative to the governed interest group, thus decreasing the intensity of the contest and $R D_{L}^{*}$. The necessary increase in the relative power of the non-governed interest group depends on its size. Thus, if the non-governed interest group is

\footnotetext{
${ }^{10}$ Since in this case, which is described in the previous footnote, there exists an interval of values of $N$ such that $R D_{A}^{*}<R D_{L}^{*}$, it is clear that if we choose the $N$ that maximizes rent dissipation under the generalized logit CSF, i.e. $N^{*}=k^{\frac{\alpha}{\alpha-1}}$, then for this size of the non-governed group $R D_{A}^{*}<R D_{L}^{*}$.
} 
small, the increase in its relative power will also be. This will bring about a small decrease in the intensity of the contest and thus a relatively small reduction in $R D_{L}^{*}$; therefore, $R D_{A}^{*}<R D_{L}^{*}$ (Part 2.a of Proposition 1). If, on the other hand, the non-governed interest group is large, the increase in its power (as a result of an increase in $k$ ) will be substantial and the intensity of the contest will decrease significantly, such that $R D_{A}^{*}>R D_{L}^{*}$ (Part 1.b of Proposition 1).

\section{Concluding remarks}

Government intervention often gives rise to contests and the contest designer is able to determine the type of contest in each case. The participating interest groups invest resources in the contest, which constitutes rent dissipation.

In the first stage, we took the size of the non-governed interest group as given and determined the rent dissipation generated by the generalized logit and APA contest success functions (Proposition 1). Since in the case of the generalized logit contest success function rent dissipation is a function of the size of the non-governed interest group, we also determined the optimal size of the non-governed interest group, which either maximizes or minimizes rent dissipation in this case (Proposition 2). We show that if the objective is to maximize rent dissipation, then there is a limit on the size of the non-governed interest group. On the other hand, if the objective is to minimize wasted resources, then the central planner may not limit the size of the nongoverned interest group under the generalized logit CSF. This would occur if the stake of each member of the non-governed interest group is equal to or larger than that of the governed interest group, regardless of the size of the non-governed interest group. The result also holds for the case in which the stake of each of the members of the non-governed interest group is smaller than that of the governed interest group and the size of the population is sufficiently large.

Our results suggest an indicator of the government's political culture, i.e. whether its members wish to maximize rent dissipation and thus put their personal wellbeing before that of society or that they view the resources invested in a contest as wasted and therefore wish to minimize rent dissipation, thus putting the welfare of society ahead of their own. The limitations imposed by legislators/regulators on the size of the non-governed interest group can provide an indication of which category they fall into. 


\section{References}

Amegashie, J.A., (2000), "Some Results on Rent-Seeking Contests with Shortlisting," Public Choice, 105 (3-4), 245-253.

Baik K.H. (2007). Contests with Groups-Specific Public-Good Prizes, Social Choice and Welfare, 30(1), pages 103-117.

Baik, K.H. (1999) "Rent-seeking firms, consumer groups, and the social costs of monopoly" Economic Inquiry 37(3), 542-554.

Baik, K.H. Kim, I. and Na S. (2001) "Bidding for a group-specific public-good prize" Journal of Public Economics 82, 415-429.

Baye, M.R., Kovenock, D. and de Vries, C. (1993) "Rigging the Lobbying Process: An Application of the All-Pay Auction" American Economic Review 83, 289 294.

Baye, Michael R. and Heidrun Hoppe, (2003), "The Strategic Equivalence of RentSeeking, Innovation, and Patent-Race Games", Games and Economic Behavior, 44(2), 217-226.

Blavatskyy, Pavlo R. (2010), "Contest Success Function with the Possibility of a Draw: Axiomatization", Journal of Mathematical Economics, 46, 267 - 276.

Che, Y.K and Gale, I., (1997), "Rent Dissipation When Rent Seekers Are Budget Constrained", Public Choice, 92, 109-126.

Che, Y.K, Gale, I., 1998. Caps on political lobbying. American Economic Review. 88, 643-651.

Che, Y.K and Gale, I., (2003), "Optimal Design of Research Contests", American Economic Review, 93(3), 646-671.

Clark, D.J., Riis, C., (1998), "Contest Success Functions: An Extension", Economic Theory, 11, 201-204.

Corchón, Luis and Dahm, Matthias. (2010), "Foundations for Contest Success Functions", Economic Theory, 43, 81-98.

Ellingsen, T. (1991) "Strategic Buyers and the Social Cost of Monopoly" American Economic Review 81(3), 648-657

Esteban, J. and Ray, D. (2001), "Collective action and the group size paradox" American Political Science Review, 663 - 672

Epstein, G.S. and Mealem, Y. (2009) “Group Specific Public Goods, Orchestration of Interest Groups with Free Riding” Public Choice 139(3), 357-369. 
Epstein, G.S. and Mealem, Y. (2011) "Governing Interest Groups and Rent Dissipation" Journal of Public Economic Theory, forthcoming.

Epstein, Gil S., Mealem, Yosef and Nitzan, Shmuel. (2011,), "Political Culture and Discrimination in Contests", Journal of Public Economics, 95, 88-93.

Epstein, Gil S.; Mealem, Yosef and Nitzan, Shmuel. (2012), "Lotteries vs. All-Pay Auctions in Fair and Biased Contests", Economics and Politics, forthcoming.

Epstein G.S. and Nitzan S., (2002), "Endogenous Public Policy, Politicization and Welfare", Journal of Public Economic Theory, 4(4), 661-677.

Epstein, G.S. and Nitzan, S. (2003) "Political culture and monopoly price determination" Social Choice and Welfare 21(1), 1-19.

Epstein, G.S. and Nitzan, S. (2006a) "Effort and performance in public policy contests" Journal of Public Economic Theory 8(2), 265-282.

Epstein, G .S. and Nitzan, S. (2006b) "The Politics of Randomness" Social Choice and Welfare 27(2), 423-433.

Epstein, G.S. and Nitzan, S. (2007) Endogenous Public Policy and Contests. Springer. Franke, J., (2012), "Affirmative Action in Contest Games", European Journal of Political Economy, 28(1), 115-118.

Franke, J., Kanzow, C., Leininger, W. and Schwartz, A. (2011) "Effort maximization in asymmetric contest games with heterogeneous contestants" Economic Theory, forthcoming.

Franke, J., Kanzow, C., Leininger, W. and Schwartz, A., (2012), "Lottery versus AllPay Auction Contests - A Revenue Dominance Theorem", Ruhr Economic Papers \#315, TU Dortmund.

Fullerton, Richard L. and R. Preston McAfee, (1999), "Auctioning Entry into Tournaments", Journal of Political Economy, 107(3), 573-605.

Glazer, A. and Hassin, R., (1988), "Optimal Contests", Economic Inquiry, 26(1), 133143.

Gradstein, M. (1995) "Intensity of competition, entry and entry deterrence in rentseeking contests" Economics and Politics 7, 79-91.

Gradstein, M., (1998), "Optimal Contest Design: Volume and Timing of Rent Seeking in Contests", European Journal of Political Economy, 14(4), 575-585.

Gradstein, M. and Konrad, K. (1999) "Orchestrating rent seeking contests” Economic Journal 109, 536-545. 
Grossman G, and Helpman, E. (2001) Special Interest Politics. Cambridge, MA, M.I.T. Press.

Hillman, A.L. and Riley, J.G. (1989) "Politically Contestable Rents and Transfers" Economics and Politics 1, 17-39.

Hirshleier, Jack and John G. Riley, (1992), "The Analytics of Uncertainty and Information", Cambridge University Press, Cambridge UK.

Hurley, T. M. and Shogren, J. F. (1998) "Effort Levels in Cournot-Nash Contests with Asymmetric Information” Journal of Public Economics 69, 195-210.

Hurley, T.M. (1998) "Rent Dissipation and efficiency in a contest with asymmetric valuation" Pubic Choice 94, 289-298

Jia, H., (2008), "A Stochastic Derivation of the Ratio Form of Contest Success Functions", Public Choice, 135, 125-130.

Jia, H., (2010), "On a Class of Contest Success Functions", The B.E. Journal of Theoretical Economics, 10(1),

Kahana, N. and Nitzan, S. (1999) "Uncertain pre-assigned non-contestable and contestable rents" European Economic Review 43, 1705-1721.

Konrad, K. (2002) "Investment in the Absence of Property Rights; the Role of Incumbency Advantages" European Economic Review 46(8), 1521-1537.

Konrad, A. K. (2004) “Bidding in hierarchies” European Economic Review 48(6), 13011308.

Konrad, Kai A. Strategy and Dynamics in Contests (London School of Economic Perspectives in Economic Analysis). Oxford University Press, USA, 2009.

Konrad, K.A. and Schlesinger, H. (1997) "Risk aversion in rent seeking and rent augmenting games" Economic Journal 107(2), 1671-1683.

Li, S and Yu, J., (2012), "Contests with Endogenous Discrimination", Economics Letters, forthcoming.

Lien, D., (1990), "Corruption and Allocation Efficiency", Journal of Development Economics, 33, 153-164.

Mealem, Y. and Nitzan, S., (2012a), "Equity and Effectiveness of Optimal Taxation in Contests under an All Pay Auction", Social Choice and Welfare, forthcoming.

Mealem, Y. and Nitzan, S., (2012b), "Differential Prize Taxation and Structural Discrimination in Contests", Working Paper No 3831, CESifo.

Moldovanu, M. and Sela, A., (2006), "Contest Architecture", Journal of Economic Theory, 126(1), 70-96 
Munster, J., (2009), "Group Contest Success Functions", Economic Theory, 41(2), 345 357.

Nitzan, S. (1994) "Modelling rent-seeking contests", European Journal of Political Economy 10(1), 41-60.

Nti, K.O. (1997) "Comparative statics of contests and rent seeking games" International Economic Review 38(1), 43-59

Nti, K.O., (2004), "Maximum Efforts in Contests with Asymmetric Valuations", European Journal of Political Economy, 20(4), 1059-1066.

Persson T, Tabellini, G. (2000) Political Economics: Explaining Economic Policy. Cambridge, M.I.T. Press.

Riaz, K., Shogren J.F. and Johnson S.R. (1995) “A general model of rent seeking for public goods" Public Choice 82, 243-259.

Runkel, M., (2006), "Optimal Contest Design, Closeness and the Contest Success Function", Public Choice, 129, 217-231.

Schmidt, T. (1992) "Rent-Seeking Firms and Consumers: An Equilibrium Analysis" Economics and Politics 4(2), 137-149.

Singh, N. and Wittman, D., (1998), "Contest Design and the Objective of the Contest Designer: Sales, Promotion, Sports Events and Patent Races", in Baye's (ed.) Advances in Microeconomics, Vol. 7, JAI Press, 139-167.

Skaperdas, S., (1996), "Contest success functions", Economic Theory, 7, 283-290.

Taylor, C.R., (1995), "Digging for Golden Carrots: An Analysis of Research Tournaments", American Economic Review, 85(4), 872-90.

Tullock, G. (1980) Efficient Rent-Seeking. In Buchanan, J.M., Tollison, R.D. and Tullock, G., Toward a Theory of the Rent-Seeking Society. College Station, TX: Texas A. and M. University Press. 1980, 97-112. 


\section{Appendix}

\section{Proof of proposition 1}

a. For $k \geq 1$.

$$
R D_{L}^{*}=\frac{\alpha N^{1-\alpha} k^{\alpha}(n+m)}{\left(N^{1-\alpha} k^{\alpha}+1\right)^{2}}<\frac{n+m}{2 k}=R D_{A}^{*}
$$

Rewriting (8), we obtain that (8) holds if the following inequality holds:

$$
N^{2-2 \alpha} k^{2 \alpha}+2 N^{1-\alpha} k^{\alpha}(1-\alpha k)+1>0
$$

Denote $z=N^{1-\alpha}$. (1a) becomes

$$
z^{2} k^{2 \alpha}-2 z k^{\alpha}(\alpha k-1)+1>0 .
$$

We now wish to find the $N$ that satisfies (3a).

If $(1 \leq) k \leq \frac{2}{\alpha}$, the determinant of (3a) is not positive and thus $z^{2} k^{2 \alpha}-2 z k^{\alpha}(\alpha k-1)+1>0$ always holds. However, if $k>\frac{2}{\alpha}$ then (3a) holds for the following values:

$$
N<\left[\frac{\alpha k-1-\sqrt{\alpha k(\alpha k-2)}}{k^{\alpha}}\right]^{\frac{1}{1-\alpha}}
$$

or

$$
N>\left[\frac{\alpha k-1+\sqrt{\alpha k(\alpha k-2)}}{k^{\alpha}}\right]^{\frac{1}{1-\alpha}}
$$

We will show that for $k>\frac{2}{\alpha}$ the first inequality is not possible; therefore, the second inequality remains. $\alpha k-1-\sqrt{\alpha k(\alpha k-2)}<1$ holds for all values of $k>\frac{2}{\alpha}$. Since $k>\frac{2}{\alpha}>1$, then $k^{\alpha}>1$. Thus, $\left[\frac{\alpha k-1-\sqrt{\alpha k(\alpha k-2)}}{k^{\alpha}}\right]^{\frac{1}{1-\alpha}}<1<N$. We conclude that if $k>\frac{2}{\alpha}$, then for $N$ that satisfies $N>\left[\frac{\alpha k-1+\sqrt{\alpha k(\alpha k-2)}}{k^{\alpha}}\right]^{\frac{1}{1-\alpha}}$ it holds that 
$R D_{L}^{*}<R D_{A}^{*} . \quad$ If $\quad N=\left[\frac{\alpha k-1+\sqrt{\alpha k(\alpha k-2)}}{k^{\alpha}}\right]^{\frac{1}{1-\alpha}}$, then $R D_{L}^{*}=R D_{A}^{*} ; \quad$ otherwise $R D_{L}^{*}>R D_{A}^{*}$

We will now show that the condition $N>\left[\frac{\alpha k-1+\sqrt{\alpha k(\alpha k-2)}}{k^{\alpha}}\right]^{\frac{1}{1-\alpha}}$ has substance. Denote $f(k)=\left[\frac{\alpha k-1+\sqrt{\alpha k(\alpha k-2)}}{k^{\alpha}}\right]^{\frac{1}{1-\alpha}}$. We will show that for all $0<\alpha<1$ and $k>\frac{2}{\alpha}, f(k)$ increases with $k$ and that when $k \rightarrow \frac{2}{\alpha}$ it holds that $f<1$ (namely $N>f$ for all $N$ ) and when $k \rightarrow \infty$, then $f \rightarrow \infty$ (thus, there exist values for which $N>f$ ). First, $\frac{\partial f}{\partial k}=\frac{1}{(1-\alpha) k^{2 \alpha}}\left\{\begin{array}{l}\left\{\alpha+0.5[\alpha k(\alpha k-2)]^{-0.5}\left(2 \alpha^{2} k-2 \alpha\right)\right\} k^{\alpha} \\ -\alpha k^{\alpha-1}\left\{\alpha k-1+[\alpha k(\alpha k-2)]^{0.5}\right\}\end{array}\right\}^{\frac{\alpha}{1-\alpha}}$ which is identical to $\frac{\partial f}{\partial k}=\frac{\alpha}{(1-\alpha) k^{\alpha}}\left[1-\alpha+\frac{1}{k}+\frac{(\alpha k-1)(1-\alpha)+\alpha}{[\alpha k(\alpha k-2)]^{0.5}}\right]^{\frac{\alpha}{1-\alpha}}>0$. Since when $k=\frac{2}{\alpha}(>2) \quad$ we $\quad$ obtain $\quad f=\left[\frac{1}{k^{\alpha}}\right]^{\frac{1}{1-\alpha}}=k^{\frac{\alpha}{\alpha-1}}=k^{\frac{2}{2-k}}<1 \quad$ and $f=\left[\frac{\alpha-\frac{1}{k}+\sqrt{\alpha\left(\alpha-\frac{2}{k}\right)}}{k^{\alpha-1}}\right]^{\frac{1}{1-\alpha}}$ therefore when $k \rightarrow \infty$ we obtain $f \rightarrow(2 \alpha)^{\frac{1}{1-\alpha}} k \rightarrow \infty$.

\section{b. For $k<1$.}

(1a) becomes:

$$
R D_{L}^{*}=\frac{\alpha N^{1-\alpha} k^{\alpha}(n+m)}{\left(N^{1-\alpha} k^{\alpha}+1\right)^{2}}<\frac{k(n+m)}{2}=R D_{A}^{*} .
$$

This inequality is identical to $N^{2-2 \alpha} k^{1+\alpha}+2 N^{1-\alpha}(k-\alpha)+k^{1-\alpha}>0$ and its determinant is $4 \alpha k^{2 \alpha}(\alpha-2 k)$. If the determinant is negative, which means that $\frac{\alpha}{2}<k(<1)$, then 
$R D_{L}^{*}<R D_{A}^{*}$. If the determinant is positive, which means that $k<\frac{\alpha}{2}$, then $R D_{L}^{*}<R D_{A}^{*}$ if:

$$
N^{1-\alpha}<\frac{2 k^{\alpha}(\alpha-k)-\sqrt{4 \alpha k^{2 \alpha}(\alpha-2 k)}}{2 k^{2 \alpha+1}} \text { or } N^{1-\alpha}>\frac{2 k^{\alpha}(\alpha-k)+\sqrt{4 \alpha k^{2 \alpha}(\alpha-2 k)}}{2 k^{2 \alpha+1}}
$$

or

$$
N^{1-\alpha}<\frac{2 k^{\alpha}(\alpha-k)-2 k^{\alpha} \sqrt{\alpha(\alpha-2 k)}}{2 k^{2 \alpha+1}} \text { or } N^{1-\alpha}>\frac{2 k^{\alpha}(\alpha-k)+2 k^{\alpha} \sqrt{\alpha(\alpha-2 k)}}{2 k^{2 \alpha+1}}
$$

or

$$
N<\left[\frac{\alpha-k-\sqrt{\alpha(\alpha-2 k)}}{k^{1+\alpha}}\right]^{\frac{1}{1-\alpha}} \text { or } N>\left[\frac{\alpha-k+\sqrt{\alpha(\alpha-2 k)}}{k^{1+\alpha}}\right]^{\frac{1}{1-\alpha}}
$$

From $a$ and $b$ we obtain Proposition 1 .

\section{Proof of Proposition 2}

The first-order condition for maximization is:

$$
\frac{\partial R D_{L}^{*}}{\partial N}=\alpha k^{\alpha}(n+m)(1-\alpha) N^{-\alpha} \frac{\left(1-k^{\alpha} N^{1-\alpha}\right)}{\left(N^{1-\alpha} k^{\alpha}+1\right)^{3}}=0 .
$$

Solving the first-order condition yields $N=k^{\frac{\alpha}{\alpha-1}}$ and it can be verified that the second-order conditions for maximization hold.

Part 1.a: For $k<1$, it holds that $N=k^{\frac{\alpha}{\alpha-1}}>1$, while for $N<k^{\frac{\alpha}{\alpha-1}}, R D_{L}^{*}$ increases with $N$ and for $N>k^{\frac{\alpha}{\alpha-1}}, R D_{L}^{*}$ decreases with $N$. Therefore, when $N_{P} \geq k^{\frac{\alpha}{\alpha-1}}$ the maximal level of $R D_{L}^{*}$ is attained by limiting the size of the non-governed interest group to $N^{*}=k^{\frac{\alpha}{\alpha-1}}$ and for $N_{P}<k^{\frac{\alpha}{\alpha-1}}$ the maximal level of $R D_{L}^{*}$ is attained at $N^{*}=N_{P}$.

Part 1.b: For $k \geq 1$, it holds that $N=k^{\frac{\alpha}{\alpha-1}} \leq 1$. Thus, for all $N>1, R D_{L}^{*}$ decreases with $N$ and the maximal level of $R D_{L}^{*}$ is attained at $N^{*}=1$. 
Part 2: For $k<1$, given the proof of 1.a, it holds that $N=k^{\frac{\alpha}{\alpha-1}}>1$. For $N<k^{\frac{\alpha}{\alpha-1}}$, $R D_{L}^{*}$ increases in $N$ and for $N>k^{\frac{\alpha}{\alpha-1}}, R D_{L}^{*}$ decreases in $N$. Thus, the minimal $R D_{L}^{*}$ is attained at a corner solution of either $N=1$ or $N^{*}=N_{P}$. We now show the conditions for obtaining each of these two solutions. The legislators/regulators will be indifferent between $N=N_{P}$ and $N=1$ when:

$$
R D_{L}^{*}\left(N_{P}\right)=\frac{\alpha N_{P}^{1-\alpha} k^{\alpha}(n+m)}{\left(N_{P}^{1-\alpha} k^{\alpha}+1\right)^{2}}=\frac{\alpha k^{\alpha}(n+m)}{\left(k^{\alpha}+1\right)^{2}}=R D_{L}^{*}(N=1)
$$

namely, if $\frac{N_{P}^{1-\alpha}}{\left(N_{P}^{1-\alpha} k^{\alpha}+1\right)^{2}}=\frac{1}{\left(k^{\alpha}+1\right)^{2}}$ which is identical to $N_{P}^{2-2 \alpha} k^{2 \alpha}-N_{P}^{1-\alpha}\left(k^{2 \alpha}+1\right)+1=0$. Denote $w=N_{P}^{1-\alpha}$ and the equation becomes $w^{2} k^{2 \alpha}-w\left(k^{2 \alpha}+1\right)+1=0$. Solving this equality, we obtain that $N_{P}=k^{\frac{2 \alpha}{\alpha-1}}$ or $N_{P}=1$. At the value of $N=k^{\frac{2 \alpha}{\alpha-1}}, R D_{L}^{*}$ decreases with $N$. Therefore:

a. If $N_{P}>k^{\frac{2 \alpha}{\alpha-1}}$, we obtain $R D_{L}^{*}\left(N_{P}\right)<R D_{L}^{*}(N=1)$ and the value that minimizes $R D_{L}^{*}$ is $N^{*}=N_{P}$ such that $R D_{L}^{*}=\frac{\alpha N_{P}^{1-\alpha} k^{\alpha}(n+m)}{\left(N_{P}^{1-\alpha} k^{\alpha}+1\right)^{2}}$.

b. If $(1<) N_{P}<k^{\frac{2 \alpha}{\alpha-1}}$, we obtain $R D_{L}^{*}\left(N_{P}\right)>R D_{L}^{*}(N=1)$ and the value that minimizes $R D_{L}^{*}$ is $N^{*}=1$ such that $R D_{L}^{*}=\frac{\alpha k^{\alpha}(n+m)}{\left(k^{\alpha}+1\right)^{2}}$.

For $k \geq 1$, from the proof of $1 . \mathrm{b}$ the maximal level of $R D_{L}^{*}$ is obtained when $N=1$. This value, $R D_{L}^{*}$, decreases as $N$ increases. Thus, the minimal $R D_{L}^{*}$ is attained at $N^{*}=N_{P}$. 